\title{
Effect of once daily and twice daily sustained release theophylline formulations on daytime variation of bronchial hyperresponsiveness in asthmatic patients
}

Marcello Ferrari, Mario Olivieri, Guido Lampronti, Lucio Bonazza, Cristina Biasin, Pantaleo Nacci, Giorgio Talamini, Vincenzo Lo Cascio

\begin{abstract}
Background - Previous studies evaluating spirometric values and symptoms have shown that once daily theophylline administered in the evening produces greater stabilisation of the airway function in asthmatic patients than the prototype theophylline given twice a day. The aim of this study was to compare the effects on bronchial responsiveness to methacholine of an ultrasustained release theophylline formulation (Diffumal-24, Malesci, Florence, Italy) administered once a day, a sustained release theophylline formulation (Theo-Dur, Recordati, Milan, Italy) administered twice a day, and placebo.

Methods - The study was performed in 12 adult patients with asthma using a randomised, double blind, three phase, crossover design. Each phase lasted seven days and was followed or preceded by at least three days of theophylline washout. Diffumal-24 was administered once a day at 20.00 hours whereas Theo-Dur was given twice a day at 08.00 hours and 20.00 hours. In each patient the total daily dose of theophylline was the same during both phases. The dose of the two active preparations was titrated to individual needs before the beginning of the study and then given in divided or once daily doses. At $08.00,14.00$, and 20.00 hours on day 7 of each phase serum theophylline concentrations were measured and spirometric tests $\left(\mathrm{FEV}_{1}\right)$ and bronchial challenge with methacholine were also performed.
\end{abstract}

Results - When the administration of Diffumal-24 was compared with that of Theo-Dur, a higher serum theophylline concentration of the former was seen in the morning whereas at 20.00 hours the reverse was true. Compared with placebo, at 08.00 hours Diffumal-24 improved FEV whereas Theo-Dur did not (difference between treatments $0.291,95 \%$ CI 0.12 to 0.45). At 08.00 hours Diffumal-24 decreased bronchial sensitivity to methacholine, expressed as a natural logarithm of $\mathbf{P D}_{20}$, to a greater extent than Theo-Dur (difference between treatments $0.54 \mathrm{log}$ units, $95 \%$ CI 0.016 to 1.08 ). The morning advantage observed with Diffumal-24 administration was not associated with a deterioration in the state of the airway during the daytime, the protective activity against methacholine during the 12 hours of the monitoring period being constant. Furthermore there was no difference in the mean $\mathrm{FEV}_{1}$ between the two treatments at 14.00 and 20.00 hours.

Conclusions - In adults with stable bronchial asthma treatment with a single dose of Diffumal-24 administered in the evening improved airflow obstruction and reduced bronchial hyperresponsiveness.

(Thorax 1997;52:969-974)

Keywords: theophylline, bronchial hyperresponsiveness, bronchial asthma.

Oral theophylline formulations are widely used in the treatment of bronchial asthma. During the past 10 years increased knowledge of the pharmacokinetics, availability of theophylline assays, and the development of sustained release formulations have led to a safer and more effective use of the drug. ${ }^{1}$ The therapeutic advantages of sustained release formulations have mainly been attributed to their ability to reduce fluctuations in plasma theophylline concentrations and, consequently, to keep serum levels of the xanthine within the narrow therapeutic range during the 24 hours. ${ }^{2}$ For this reason, slow release theophylline formulations given twice a day are theoretically more effective than the more recently introduced ultrasustained release theophylline formulations designed to allow once a day dosing which produce larger fluctuations in serum levels of the xanthine. ${ }^{34}$

The concept that the smaller the fluctuations in serum theophylline levels the better is the control of asthma symptoms is based on the assumption that airway requirements for treatment and airway function are the same during the night and the day. However, most patients with asthma have a significant increase in the daytime variations of airway calibre and airway hyperresponsiveness and have significant worsening of their symptoms at night and in the early morning. ${ }^{5-9}$

It has been suggested that an ideal bronchodilator should have its maximal effect at the time of the greatest bronchial obstruction and hyperresponsiveness. ${ }^{10}$ This can be attained by administering a once a day formulation in the evening which results in higher serum levels in the night and early morning. ${ }^{10}$ 
Table 1 Patient characteristics

\begin{tabular}{lllllll}
\hline $\begin{array}{l}\text { Patient } \\
\text { no. }\end{array}$ & Sex & $\begin{array}{l}\text { Age } \\
\text { (years) }\end{array}$ & $\begin{array}{l}\text { Smoking } \\
\text { history }\end{array}$ & $\begin{array}{l}F E V_{1} \\
(\% \text { pred })\end{array}$ & $\begin{array}{l}P D_{20} \\
(\mu g)\end{array}$ & $\begin{array}{l}\text { Daily heophylline dose } \\
(\text { mg/24h) }\end{array}$ \\
\hline 1 & $\mathrm{~F}$ & 51 & $\mathrm{~N}$ & 71 & 506 & 600 \\
2 & $\mathrm{M}$ & 62 & $\mathrm{~N}$ & 78 & 450 & 900 \\
3 & $\mathrm{M}$ & 56 & $\mathrm{~N}$ & 94 & 296 & 700 \\
4 & $\mathrm{M}$ & 55 & $\mathrm{~N}$ & 75 & 25 & 900 \\
5 & $\mathrm{M}$ & 40 & $\mathrm{E}$ & 74 & 80 & 800 \\
6 & $\mathrm{M}$ & 28 & $\mathrm{~N}$ & 83 & 155 & 600 \\
7 & $\mathrm{M}$ & 29 & $\mathrm{E}$ & 77 & 178 & 700 \\
8 & $\mathrm{~F}$ & 54 & $\mathrm{~N}$ & 72 & 46 & 600 \\
9 & $\mathrm{M}$ & 23 & $\mathrm{~N}$ & 99 & 110 & 700 \\
10 & $\mathrm{~F}$ & 33 & $\mathrm{~N}$ & 95 & 25 & 600 \\
11 & $\mathrm{M}$ & 26 & $\mathrm{~N}$ & 95 & 60 & 700 \\
12 & $\mathrm{~F}$ & 55 & $\mathrm{~N}$ & 85 & 116 & 700 \\
Mean (SE) & & $41.5(4.0)$ & & $84.0(2.6)$ & $170.5(46.8)$ & $708.3(31.3)$
\end{tabular}

$\mathrm{N}=$ never smoker; $\mathrm{E}=$ ex-smoker.

Previous studies evaluating spirometric values and symptoms have shown that once a day theophylline administered in the evening produced greater stabilisation of airway function than the prototype theophylline formulation given twice a day to asthmatic patients. ${ }^{10}$ In recent years emphasis on bronchial hyperresponsiveness as an important feature of asthma has become generally accepted. ${ }^{1213}$ We have therefore compared the effects on bronchial hyperresponsiveness in adult patients with asthma of once a day theophylline administered in the evening with that of a reference theophylline formulation given twice a day.

\section{Methods}

SUBJECTS

Twelve non-smoking asthmatic subjects (eight men) of mean age 41.5 years (range 23-62) took part in the study (table 1 ). The diagnosis had been established using the criteria defined by the American Thoracic Society. ${ }^{14}$ Respiratory symptoms were well controlled by administration of theophylline or inhaled $\beta$ agonists which were part of their therapeutic regimen. Treatment with drugs affecting bronchial responsiveness such as steroids or inhaled cromolyn had been suspended during the month before the beginning of the study if the patient had been taking them previously. Eight had a positive skin test reaction to aeroallergens but were not exposed to the relevant allergens during the study. Pregnant patients or nursing mothers were excluded as were patients with clinically significant cardiac, renal, hepatic or metabolic disease. All subjects had proven airway hyperresponsiveness - that is, a $20 \%$ decrease in forced expiratory volume in one second $\left(\mathrm{FEV}_{1}\right)$ with $\leq 1500 \mu \mathrm{g}$ methacholine (the method of methacholine challenge is described below). Basal $\mathrm{FEV}_{1}$ values were above $70 \%$ of the predicted value ${ }^{15}$ for all subjects. Patients gave written informed consent prior to participation in the study.

DRUGS AND TRIAL DESIGN

The test medications were Theo-Dur $(200 \mathrm{mg}$, twice daily sustained release theophylline tablets; Recordati Spa, Milan, Italy) and Diffumal$24(200 \mathrm{mg}$, once daily sustained release theophylline tablets; Malesci Spa, Florence, Italy).
Diffumal-24 is an ultrasustained release theophylline formulation that produces peak theophylline concentration 10 hours after the oral administration of $600 \mathrm{mg}$ (personal unpublished results). All the tablets could be broken in half. A matching placebo was also used to allow the study to be blind.

The study began with a theophylline dosage titration period. While taking their pretrial slow release theophylline twice a day each patient had his/her dosage adjusted, if necessary, to produce morning theophylline concentrations of $\geq 8 \mathrm{mg} / \mathrm{l}$. This theophylline dose was then administered as a single dose of Diffumal-24 at 08.00 hours or divided into two doses of Theo-Dur at 08.00 and 20.00 hours.

The study was of a double blind, crossover, placebo controlled design. Patients were assigned to treatments according to a $3 \times 3$ latin square design and received orally for seven days, in three separate periods, either placebo, once daily sustained release theophylline, or the same dosage of twice daily sustained release theophylline. The placebo and both once daily and twice daily theophylline formulations were contained in identical wafers. The procedure was as follows: (1) two wafers containing placebo in the morning and two in the evening; (2) two wafers containing Theo-Dur at 08.00 hours and two at 20.00 hours; (3) two wafers containing placebo at 08.00 hours and two wafers containing Diffumal-24 at 20.00 hours. The three treatment periods were separated by a washout period of at least three days.

Inhaled $\beta$ agonists were continued throughout the trial and patients were asked to keep the daily dosage of these medications constant until the seventh day of each treatment period at which time they were withheld for 12 hours before performing spirometric tests and the methacholine challenge. Drugs known to affect theophylline metabolism were withdrawn three weeks before the onset of the study and were not allowed during the trial. The patients were asked to refrain from coffee and tea and from any medication containing xanthines (except the study drugs as specified). On the seventh day of each treatment period the patients underwent spirometric tests and bronchial challenge with methacholine at 08.00, 14.00, and 20.00 hours At these times blood samples were taken for theophylline analysis.

SPIROMETRIC TESTING AND BRONCHIAL

CHALLENGE

Forced expiratory volume in one second $\left(\mathrm{FEV}_{1}\right)$ was measured using a water sealed spirometer (Biomedin, Padua, Italy) and the bronchial challenge with methacholine was carried out using an ampoule dosimeter device (Mefar, Brescia, Italy). The dosimeter was triggered by an inspiration activated solenoid valve which remained open for one second to allow the generation of an aerosol with pressured air of $1.5 \mathrm{~kg} / \mathrm{cm}^{2}$. Two solutions of methacholine (Sigma Chemie, $0.1 \%$ and $1.0 \%$, respectively) in a phosphate buffer were prepared daily. After an initial inhalation of phosphate buffer only, methacholine was inhaled by 
the subjects in doses ranging from $20 \mu \mathrm{g}$ to a total cumulative dose of $2000 \mu \mathrm{g}$. The dose was increased by changing the methacholine concentration and/or the number of breaths. $\mathrm{FEV}_{1}$ was determined immediately before the challenges, after inhalation of the buffer, and after each inhalation of methacholine. The methacholine test was ended when $\mathrm{FEV}_{1}$ fell more than $20 \%$ compared with the value measured after the buffer challenge. The results of the bronchial challenge were expressed by the dosage of methacholine causing a $20 \%$ fall of $\mathrm{FEV}_{1}\left(\mathrm{PD}_{20}\right)$. We calculated this datum by interpolating in the semilogarithmic dose-response curve, the point corresponding to the dose causing the fall in $\mathrm{FEV}_{1}$ just below $20 \%$ with the point corresponding to the dose causing the $\mathrm{FEV}_{1}$ just above it.

SERUM THEOPHYLLINE MEASUREMENTS

Blood samples for theophylline assay were collected from a forearm vein at 08.00, 14.00, and 20.00 hours on the seventh day of each treatment period. Samples were coded so the technician did not know which preparation was represented by any given sample. Serum theophylline concentrations were assayed in duplicate by means of a homogenous enzyme immunoassay (Emit, Syva Inc, Palo Alto, California, USA). The coefficient of variation for theophylline assay was $4.9 \%$. From the serum theophylline concentrations over time, the area under the curves (AUC) was calculated by linear trapezoidal rule.

STATISTICAL ANALYSIS

The data are expressed as mean (SE) values. Analysis of variance (ANOVA) for repeated measures was first performed to assess the relevance of various factors (treatment, time of sample collection, and treatment by time interaction) in explaining the observed changes in $\mathrm{FEV}_{1}, \mathrm{PD}_{20}$ and theophylline serum levels. $\mathrm{PD}_{20}$ values were log transformed (natural logarithm, $\ln P D_{20}$ ) before the analysis. If the interaction term was statistically significant - that is, the relative effects of treatments varied markedly at different sample times - thus leading to incorrect estimates of treatment and time effects, separate analysis by treatment and by time was performed. A Duncan test for multiple comparisons was used to assess the grouping of treatments and times when the corresponding ANOVA F test was significant at the specified alpha level.

\section{Results}

SERUM THEOPHYLLINE CONCENTRATIONS AND $\beta$ AGONIST USE

The mean daily theophylline dose during the trial period was $708.3 \mathrm{mg}$ (range $600-900 \mathrm{mg}$ ). The mean theophylline concentrations are shown in fig 1 . The interaction term treatment by time was statistically significant $(\mathrm{p}<0.001)$.

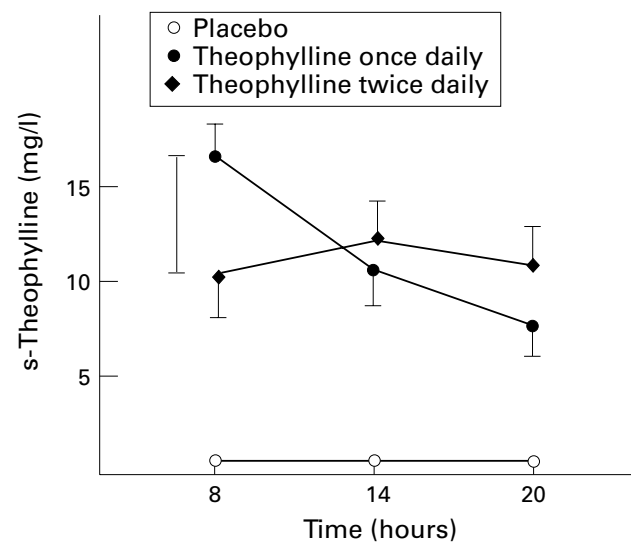

Figure 1 Mean (SE) steady state serum theophylline concentrations in 12 asthmatic patients during treatment with once daily slow release theophylline (Diffumal-24) administered at 20.00 hours and twice daily slow release theophylline (Theo-Dur) administered at 08.00 and 20.00 hours. During the placebo treatment period serum theophylline levels were unmeasurable. The measurements were taken on day 7 of treatment. At 08.00 hours and at 20.00 hours serum levels of theophylline after the two active drugs were significantly different $(p<0.001$ and $p<0.01$, respectively).

Serum theophylline concentrations were undeterminable during the placebo treatment period in all the patients. Diffumal-24 produced a significantly higher serum theophylline concentration than Theo-Dur at 08.00 hours (16.6 (1.1) versus 10.1 (0.6) $\mathrm{mg} / \mathrm{l}, \mathrm{p}<0.001)$. However, at 20.00 hours serum theophylline levels after Theo-Dur (10.8 (1.0) $\mathrm{mg} / \mathrm{l})$ were higher than those seen after Diffumal-24 (8.3 $(0.7) \mathrm{mg} / \mathrm{l}, \mathrm{p}<0.01)$. No difference in theophylline concentration between the two drugs was found at 14.00 hours (Theo-Dur, 12.3 (1.0) $\mathrm{mg} / \mathrm{l}$; Diffumal-24, $11.2 \quad(0.9) \mathrm{mg} / \mathrm{l})$. Within-drug comparison revealed that during the Diffumal-24 treatment period the mean serum theophylline concentrations at 08.00 , 14.00 , and 20.00 hours were significantly different from one another $(p<0.01)$. During Theo-Dur dosing there was no difference between the mean concentrations of theophylline measured at 08.00 hours and 20.00 hours, but at 14.00 hours the mean concentration was significantly higher.

The relative bioavailabilities of theophylline measured over the 12 hour period were similar with both therapeutic regimens, the Theo-Dur to Diffumal-24 ratio of the area under the concentration-time curve being 0.96 .

At 08.00 hours one patient had a serum theophylline concentration below $8 \mathrm{mg} / 1$ $(7.8 \mathrm{mg} / \mathrm{l})$ after treatment with Theo-Dur, and one patient had a serum theophylline concentration above $20 \mathrm{mg} / 1(23 \mathrm{mg} / \mathrm{l})$ after treatment with Diffumal-24. No patient complained of clinically significant adverse effects following administration of theophylline.

The mean daily dosage of inhaled $\beta$ agonist was one puff three times daily. The patients were asked to keep the daily dosage constant and no difference in the frequency of $\beta$ agonist use was found during the three treatment periods. 


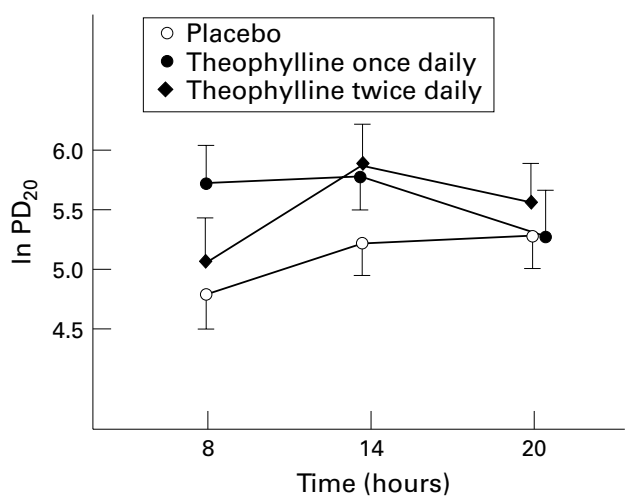

Figure 2 Effect of treatment with once daily slow release theophylline (Diffumal-24) administered at 20.00 hours, twice daily slow release theophylline (Theo-Dur) administered at 08.00 and 20.00 hours and placebo on $\operatorname{lnPD}_{20}$. The bars indicate standard error. The measurements were taken on day 7 of treatment. The differences between $\ln P D_{20}$ measured at 08.00 hours after Diffumal-24 and placebo, and at the same time after Diffumal-24 and Theo-Dur were statistically significant $(p<0.01$ and $p<0.05$, respectively).

BRONCHIAL CHALLENGE WITH METHACHOLINE The changes in methacholine hyperresponsiveness expressed as $\ln \mathrm{PD}_{20}$ are shown in fig 2 . In table 2 the differences at each time between treatments, with $95 \%$ confidence interval (CI), are reported. The interaction term treatment by time was statistically significant $(\mathrm{p}<0.05)$.

During placebo administration the mean values of $\ln P D_{20}$ were $4.70(0.28)$ at 08.00 hours, $5.01(0.34)$ at 14.00 hours and $5.35(0.32)$ at 20.00 hours. The $\ln \mathrm{PD}_{20}$ measured at 08.00 hours was significantly lower than that obtained at 20.00 hours $(\mathrm{p}<0.01)$ whereas no difference was found between the values recorded at any other time.

With Theo-Dur the $\ln \mathrm{PD}_{20}$ was increased, though not significantly $(5.18(0.31)$ at 08.00

Table 2 Analysis of differences in $\operatorname{lnPD} D_{20}$ between treatments at 08.00, 14.00, and 20.00 hours

\begin{tabular}{llrr}
\hline $\begin{array}{l}\text { Time } \\
\text { (hours) }\end{array}$ & Treatment & Mean & \multicolumn{1}{l}{$95 \%$ CI } \\
\hline 08.00 & Once daily SRT vs placebo & 1.034 & 0.618 to 1.450 \\
& Twice daily SRT vs placebo & 0.486 & -0.015 to 0.988 \\
& Once daily SRT vs twice daily SRT & 0.548 & 0.016 to 1.082 \\
\multirow{2}{*}{14.00} & Once daily SRT vs placebo & 0.749 & -0.089 to 1.588 \\
& Twice daily SRT vs placebo & 0.808 & -0.092 to 1.523 \\
& Once daily SRT vs twice daily SRT & -0.058 & -0.788 to 0.671 \\
20.00 & Once daily SRT vs placebo & 0.029 & -0.604 to 0.662 \\
& Twice daily SRT vs placebo & 0.265 & -0.495 to 1.025 \\
& Once daily SRT vs twice daily SRT & -0.236 & -1.037 to 0.565 \\
\hline
\end{tabular}

$\mathrm{SRT}=$ slow release theophylline.

Table 3 Analysis of differences in FEV between treatments at 08.00, 14.00, and 20.00 hours

\begin{tabular}{llrr}
\hline $\begin{array}{l}\text { Time } \\
\text { (hours) }\end{array}$ & Treatment & Mean & $95 \%$ CI \\
\hline 08.00 & Once daily SRT vs placebo & 0.292 & 0.126 to 0.457 \\
& Twice daily SRT vs placebo & 0.141 & -0.101 to 0.383 \\
& Once daily SRT vs twice daily SRT & 0.151 & -0.077 to 0.379 \\
\multirow{2}{*}{ (4.00 } & Once daily SRT vs placebo & 0.078 & -0.083 to 0.239 \\
& Twice daily SRT vs placebo & 0.093 & -0.127 to 0.313 \\
& Once daily SRT vs twice daily SRT & 0.015 & -0.113 to 0.144 \\
& Once daily SRT vs placebo & 0.036 & -0.238 to 0.309 \\
& Twice daily SRT vs placebo & 0.107 & -0.143 to 0.357 \\
& Once daily SRT vs twice daily SRT & -0.143 & -0.363 to 0.078 \\
\hline
\end{tabular}

SRT $=$ slow release theophylline.

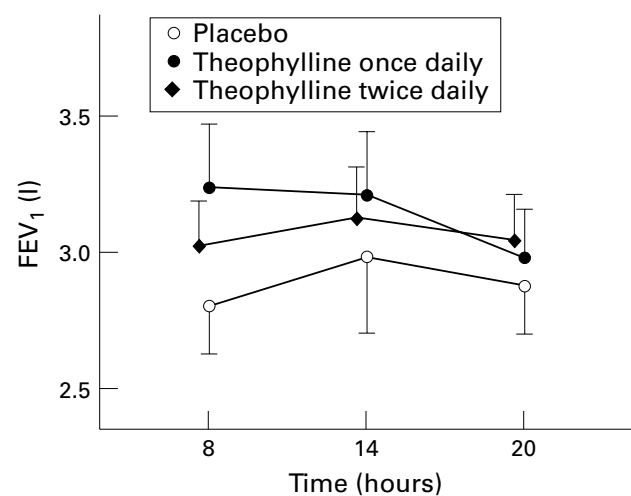

Figure 3 Mean (SE) values of FEV in 12 asthmatic patients during treatment with once daily slow release theophylline (Diffumal-24) administered at 20.00 hours, twice daily slow release theophylline (Theo-Dur) administered at 08.00 and 20.00 hours, and placebo. The measurements were taken on day 7 of treatment. The difference between FEV $V_{1}$ measured at 08.00 hours after Diffumal-24 and placebo was statistically significant $(p<0.01)$.

hours, $5.81(0.37)$ at 14.00 hours, $5.6(0.36)$ at 20.00 hours) relative to placebo at each testing time. During Diffumal-24 treatment $\ln \mathrm{PD}_{20}$ values were $5.73(0.36), 5.75(0.47)$, $5.29(0.44)$ at $08.00,14.00$, and 20.00 hours, respectively. At 08.00 hours the differences between $\ln P D_{20}$ values recorded after Diffumal24 and placebo and after Diffumal-24 and Theo-Dur were statistically significant $(\mathrm{p}<0.01, \mathrm{p}<0.05$, respectively; table 2$)$. No difference between treatments was found at 14.00 hours and 20.00 hours. When the patients with theophylline serum levels below $8 \mathrm{mg} / 1$ were withdrawn from the analysis the difference between the effect of Diffumal-24 and Theo-Dur on methacholine induced bronchoconstriction at 08.00 hours was still significant.

Diffumal-24 stabilised the bronchial response to methacholine so that there was no significant difference between the mean values of $\ln \mathrm{PD}_{20}$ at $08.00,14.00$, and 20.00 hours. However, during Theo-Dur treatment the mean values of $\ln \mathrm{PD}_{20}$ at 08.00 hours were significantly lower than at 14.00 hours $(\mathrm{p}<0.05)$.

$\mathrm{FEV}_{1}$

The mean $\mathrm{FEV}_{1}$ values at each measurement time after placebo, Theo-Dur, and Diffumal24 are shown in fig 3 and in table 3 the differences at each time between treatments with 95\% CI are reported. The interaction term treatment by time was statistically significant $(\mathrm{p}<0.03)$.

After placebo the mean (SE) $\mathrm{FEV}_{1}$ values were $2.8(0.2), 3.0(0.3), 2.9(0.3) 1$ at 08.00 , 14.00 , and 20.00 hours, respectively. There was no statistically significant difference in $\mathrm{FEV}_{1}$ between any time points while on placebo. The once daily theophylline formulation (Diffumal24) resulted in significantly higher $\mathrm{FEV}_{1}$ values at 08.00 hours $(3.2(0.3) 1)$ than at 20.00 hours (2.9 (0.2) $1 ; \mathrm{p}<0.02)$ which, in turn, were significantly lower than at 14.00 hours $(3.1(0.3) 1$; 
$\mathrm{p}<0.01)$. During the Theo-Dur treatment period there were no significant differences between $\mathrm{FEV}_{1}$ at 08.00 hours (3.0 (0.2) 1), 14.00 hours (3.1 (0.2) 1$)$, and 20.00 hours (3.0 (0.2)1). The once a day formulation of theophylline produced significantly greater bronchodilation than placebo at 08.00 hours $(p<0.01)$ whereas the twice a day formulation did not. No significant difference was found in $\mathrm{FEV}_{1}$ between treatments at 14.00 hours and 20.00 hours

\section{Discussion}

During placebo administration the lowest mean values of $\mathrm{PD}_{20}$ were found at 08.00 hours with a progressive increase in the parameter at 14.00 and 20.00 hours, consistent with previous reports of diurnal variation in airway responsiveness. ${ }^{916}$ Despite the substantial morning fall in $\mathrm{PD}_{20}$ there was no significant daytime variation in $\mathrm{FEV}_{1}$. These data support the hypothesis that the increase in bronchial responsiveness is not dependent on, or need not result in, airflow obstruction. ${ }^{17}$

The administration of the once daily theophylline formulation at 20.00 hours produced a decrease in the morning sensitivity to methacholine that was significantly greater than that seen after the twice daily regimen. The better protective effect of Diffumal-24 compared with Theo-Dur may be due to the higher serum theophylline concentrations obtained at 08.00 hours and suggests a dose-related effect of theophylline on bronchial hyperresponsiveness. ${ }^{18-20}$ Another explanation for the better protective effect against methacholine seen with Diffumal-24 might be the higher mean $\mathrm{FEV}_{1}$ values registered at 08.00 hours after administration of the once daily theophylline (see below). However, the difference between $\mathrm{FEV}_{1}$ value at 08.00 hours after Theo-Dur and Diffumal-24 was slight and not statistically significant so an alternative hypothesis, such as an effect of theophylline on bronchial responsiveness not dependent on its bronchodilating activity, cannot be excluded.

The morning advantage of this particular once a day theophylline formulation - that is, the greater effect on airways at 08.00 hours in comparison with the conventional twice daily theophylline treatment - was not associated with a deterioration in the state of the airway during the day; the protective activity against methacholine of Diffumal-24 and Theo-Dur at 14.00 hours and 20.00 hours was not significantly different even if higher theophylline serum levels were attained at 20.00 hours with the twice a day formulation. Furthermore, even though the fluctuation in serum theophylline concentration was considerably greater during treatment with the once a day theophylline formulation, the variability over 24 hours in $\mathrm{PD}_{20}$ was far less, indicating a greater stability of bronchial hyperresponsiveness with the evening administration of the once daily theophylline formulation. These findings indicate that, when low grade airway reactivity is present (as in the evening), it is unnecessary to attain high theophylline serum concentrations. On the contrary, it is of critical importance to produce the maximum serum theophylline concentrations in the early morning which is the time when bronchial hyperresponsiveness is highest.

Our study therefore adds a further piece of evidence in favour of the concept that optimal control of asthma requires that maximum concentrations of theophylline are achieved at the time of the patient's greatest need for airway protection $^{11}$ rather than minimisation of fluctuation in serum levels of the drug. ${ }^{2122}$

After evening administration of the once a day formulation there was a significant increase in $\mathrm{FEV}_{1}$ values in the morning compared with placebo which did not occur after Theo-Dur. However, no difference between the effect of the two theophylline products was found at 14.00 and 20.00 hours. These findings confirm previous studies showing that once daily theophylline therapy is as effective or more so than twice daily therapy for controlling asthma ${ }^{23-28}$ in patients with severe ${ }^{11}$ or moderately severe ${ }^{1028}$ airflow limitation. They also show that the drug has a similar benefit in patients with mild bronchial obstruction.

After treatment with the once a day theophylline formulation only one subject had theophylline serum levels above $20 \mathrm{mg} / 1$ in the morning. We cannot exclude that serum concentrations above the therapeutic range might have occurred in other patients during the night, even though none complained of clinically relevant adverse effects. This point must be carefully considered when the total dose of theophylline is administered in the evening.

The design of our study did not enable us to check for carry over effects of treatment. However, carry over effects are unlikely since a washout period of at least three days (which in many patients lasted for 4-6 days) seems adequate to eliminate theophylline completely in patients without cardiac or hepatic disease.

In conclusion, our results have shown that a once a day theophylline formulation taken in the evening compared with a twice a day formulation results in a higher serum theophylline concentration in the morning when maximum airway narrowing and hyperresponsiveness occur. This improves bronchial obstruction and significantly reduces sensitivity to methacholine in the morning without a deterioration in the state of the airways during the daytime. Although it is tempting to speculate that the clinical use of a theophylline ultrasustained release formulation is justified by its efficacy in decreasing bronchial hyperresponsiveness as well as its established bronchodilator effectiveness, ${ }^{1}$ long term studies are necessary to support this hypothesis definitively. Moreover, further investigations are needed to clarify whether the results obtained in our patients might be applied to subjects with more severe disease and/or with more severe bronchial hyperresponsiveness.

1 Hendeles L, Weinberger M. Theophylline: a state of the art review. Pharmacol Ther 1973;3:2-44.

2 Tabachnik E, Scott P, Correia J. Sustained-release theophylline: a significant advance in the treatment of childhood asthma. F Pediatr 1982;100:484-92. 
3 Barr WH. The once daily theophylline controversy. Pharmacotherapy 1984;4:167-8.

4 Weinberger MM. Theophylline QID, TID, BID and now QD? Pharmacotherapy 1984;4:181-8

5 Hetzel MR, Clark TJH, Houston K. Physiological patterns in early morning asthma. Thorax 1977;32:418-23.

6 Clark TJH, Hetzel MR. Diurnal variation of asthma. $\mathrm{Br} f$ Dis Chest 1977;71:87-92.

7 Li JTC, Reed CE. Nocturnal asthma and timing of treatment. Am f Med 1985;79(Suppl 6A):10-15.

8 DeVries K, Goei JT, Booy-Noord H, Orie NGM. Changes during 24 hours in the lung function and histamine hyperreactivity of the bronchial tree in asthmatic and bronchitis patients. Int Arch Allergy 1962;20:93-101.

9 Rachiele A, Malo JL, Cartier A, Pineau L, Ghezzo M, Martin RR. Circadian variations of airway response to histamine in asthmatic subjects. Bull Eur Physiopathol Respir 1983;19:465-9.

10 D'Alonzo GE, Smolensky MH, Feldman S, Gianotti LA, Emerson BM, Staudinger H, Steinijans VW. Twenty-four hour lung function in adult patients with asthma. Am Rev Respir Dis 1990;142:84-90.

11 Arkinstall WW, Atkins ME, Harrison D, Stewart JH. Once daily sustained-release theophylline reduces diurnal variation in spirometry and symptomatology in adult asthma. ation in spirometry and symptomatolog

12 Boushey HA, Holtzman MJ, Sheller JR, Nadel JA. Bronchial hyperreactivity. Am Rev Respir Dis 1980;121:389-413.

3 Reed C, Townley R. Asthma: classification and pathogenesis. In: Middleton E Jr, Reed CE, Ellis EF, eds. Allergy: principles and practice. 2 nd ed. St. Louis: CV Mosby, 1983:811-23.

14 American Thoracic Society. Chronic bronchitis, asthma and pulmonary emphysema. A statement by the committee and diagnostic standards for non tuberculous respiratory diseases. Am Rev Respir Dis 1962;85:762-8.

15 Commission des Communautes Europennes (CECA). Tables de references pour les examens spirographiques. LuxTables de references pour les examens spirographiques. Lux-
embourg, Service des Publications des Communautes embourg, Service

16 Barnes P, Fitzgerald G, Brown M, Dollery C. Nocturnal asthma and changes in circulatory epinephrine, histamine and cortisol. N Engl f Med 1980;303:263-7.
17 Van Aalderen WM, Postma DS, Koeter GH, Knol K. Circadian change in bronchial responsiveness and airflow obstruction in asthmatic children. Thorax 1989;44:803-7

18 Fink JN, Levy MB, Conrad E. A study of two controlled release theophylline preparations (abstract). Am $\mathcal{F ~ M e d ~}$ 1985;7(Suppl 6):58-61.

19 Fairshter RD, Bhola R, Thomas R. Comparison of clinical effects and pharmacokinetics of once daily Uniphyl and twice-daily Theo-dur in asthmatic patients. $A m \mathcal{F} \mathrm{Med}$ 1985;7(Suppl 6):48-53.

20 Rivington RN, Calcutt L, Child S, MacLeod JP, Hodder $\mathrm{RV}$, Stewart JH. Comparison of morning versus evenin dosing with a new once-daily oral theophylline formulation: Uniphyl tablets. Am f Med 1985;7(Suppl 6): 67-72.

21 Petty TL, Rollins DL. Theophylline levels and clinical response in asthmatic adults receiving long-term Uniphyl. Am F Med 1985;79 (Suppl 6):73-6.

22 Tinkleman DG, Miller E, Janky DG, Decouto J, Edelman LA. Comparative trial of the clinical efficacy and pharmacokinetics of 12-hour and 24 hour controlled release theophylline preparations in patients with chronic asthma. Ann Allergy 1985;55:571-6.

Ann Allergy 1985;55:571-6.
23 Welsh PW, Reed CE, Conrad E. Timing of once a-day theophylline dose to match peak blood level with diurnal variation in severity of asthma. Am f Med 1986;80:1098102 .

Magnussen H, MD, Reuss G, Jorres R, MS. Methylxanthines inhibit exercise-induced bronchoconstriction at low serum theophylline concentration and in a dose dependent fashion. F Allergy Clin Immunol 1988;81:531-7.

25 Koeter GH, Krann J, Boorsma M, Jonkman JHG, Van Der Mark THW. Effect of theophylline and enprofylline on bronchial hyperresponsiveness. Thorax 1989;44:1022-6.

26 Ferrari M, Olivieri M, Lampronti G, Biasin C, Lo Cascio V. Effect of three different doses of a slow-release theophylline formulation on bronchial response to inhaled methacholine in asthmatic patients. Respiration 1995;65 95-100.

27 Weinberger $M$, Hendeles L, Wong L, Vaughn L. Relationship of formulation and dosing interval to fluctuation of serum theophylline concentration in children with chronic asthma. F Pediatr 1981;99:145-52.

28 Isles AF, MacLeod SM, Levison H. Theophylline: new thoughts about an old drug. Chest 1982;1(Suppl):49-54. 